\title{
CULTURAL VALUE ORIENTATIONS AND SATELLITE TELEVISION PREFERENCE IN NIGERIA
}

\author{
Olowe, Temitope S. \\ Department of Marketing \\ The Federal Polytechnic, Ado Ekiti, Nigeria \\ Email: olotemitope@gmail.com \\ Esiti, Blankson Governor \\ Department of Petroleum Marketing \& Business Studies \\ Petroleum Training Institute, Effurun, Nigeria
}

\begin{abstract}
Culture comprises the whole complex of distinctive spiritual, intellectual and emotional features that characterize society, our thought about life, and our ideas. Culture shape the way we see world; it has capacity to bring about the change of attitudes needed to ensure peace and sustainable development which is known as the only possible way forward for life on planet earth. Considering the prominence of Satellite television as a virtual medium, this study sought to know the influence of media imperialism and the claim that it has affected and undermined local Nigerian norms and values. More so, this study examined the cultural value orientation and satellite television preference in the south-western states of Nigeria, the region that is fully immersed with her culture. It specifically examined how satellite television has affected the knowledge, belief, art, morals, law, customs and any other capabilities and habits acquired by Nigerians as a member of the society. The research methodology utilizes descriptive statistics with a self-designed questionnaire used to elicit information from a sample of 180 respondents. The formulated hypotheses were tested at 0.05 level of significance using multiple regressions. The findings of the study revealed that the relationship between satellite television preferences and cultural value orientation is high, positive and statistically significant. It was therefore recommended among others that television operators and producers should revamp the culture through interesting educative programme.
\end{abstract}

KEYWORDS: cultural value orientations, consumer preference, satellite television, nigeria.

\section{INTRODUCTION}

The influence of technological development is changing the present world very rapidly and these changes have ripple effects on every spheres of human life with pronounced effects on the social and cultural belief systems. The advent of new technology in television medium thwarted everything; information now flows across national boundaries, hence the dilution of strict adherence to cultural instincts. The introduction of Satellite television is one of the dimensions of this technological advancement which has a definite effect on the social and cultural orientations of human beings, around the world. For these changes, human behavior is also changing and therefore, the study of changes in the human behavior is becoming more important in the present business world. 
Since the colonial era, Nigeria has been experiencing cultural inversion; foreign culture has eroded the cultural heritage of the people; with the satellite television, it is rising on an increasing rate. The dilution of original culture is evident in youth dressing patterns, spoken words and other social adaptations. Many Nigerians have obvious preference to western style of dressing than indigenous dressing due to over indulgence in the consumption of western media content. Youths prefer to wear western dresses, speak with foreign accents, play foreign music and watch their movies so much so that they perceive themselves to be westerners (Okonkwo, 2008).

Many Nigerians have obvious preference to western style of dressing than indigenous dressing due to over indulgence in consuming western media content. Contrarily, Baran (2010) insists that though the problem with globalized television is undisputable, the internal government regulation, over infiltration of foreign media and its content has helped to keep erosion of indigenous cultures in check. Furthermore, the millennials are enjoying foreign programs with great attraction ignoring their own cultural programs. They are also getting used to the foreign lifestyles which are detrimental to the social norms and values of Nigerians especially the south-westerners, who adhere strongly to their culture as a way of life. Various satellite television channels have captured the attention of viewers in south-west, Nigeria and exposed them to programs that are vividly in tandem with their cultural beliefs and norms, resulting to cultural erosion and cultural hybridization. Therefore, it is becoming imperative to conduct a study on how preference for Satellite television is affecting the cultural value orientations of people in the South-Western states of Nigeria.

\section{Statement of the Problem}

In recent times, there has been a huge concern over the Nigerian culture which seems to be taking a downward plunge among the average Nigerians. Trends and patterns have emerged in their food habits, mode of dressing and sexual orientation that is not consistent with known Nigerian cultural orientations (Akintayo \& Adebola, 2015). Values that are supposed to define and guide the overall behaviour of Nigerians seems to be daily neglected. Since there is no school or subject that teaches the need to discountenance established cultural values, where food, dress and sexuality are concerned, it is not impossible that these changes in attitude and behaviour may be connected with the western television programs that Nigerians are exposed to via Satellite television.

According to O'Donnell (2007) television programs reflect a society's values, norms and practices as well as fads, interest and trends. Western television programs largely reflect the western culture through their Programs and this appears to be mis-guiding unsuspected Nigerians who watch such programmes. For example, Fashion Television and Style are entertainment stations that deal with fashion and lifestyle in western countries. These stations makes youths increasingly aware of fashion trends and there seems to be the urge to try to keep up with the standards of the westerners. Also, music and music videos are not excluded as there are some musical contents on Multichoice' DSTV that overtly depict sexual promptings; this can be seen on channels like MTV base, Trace and Sound City. Languages such as being 'hot and sexy' for example has become new trends among viewers and may have contributed not just to the increased rate of indecent dressing and uncontrollable urge for sex which is prevalent among subscribers in South-Western Nigeria. All these factors seem to derogate the cultural values among people in the South-Western Nigeria. Hence, this study will among other things, 
examine the extent to which Satellite television programmes is responsible for some of the emerging behavioural and attitudinal changes among Nigerian subscribers in South-Western Nigeria.

The influence of television on humanity is encompassing. Several works have observed the psychological aspects of watching television. People are affected differently especially the youths, depending on the information type and exposure level (Obono \& Madu, 2010). Therefore, there is the fear of propaganda and transmission of provocative material that can increase tension domestically and internationally and the promotion of cultural imperialism. It is on this note that this research investigates the effect of preference of Satellite television on the cultural value orientation of people in the South-Western states of Nigeria and its implication on our cultural values, using Ekiti, Ondo and Osun State as a case study.

\section{Objectives of the Study}

The broad objective of this study is to empirically investigate the influence of Cultural value orientations on Satellite television preference among the Satellite television customers in southwestern, Nigeria. The study specifically sought to:

i. Examine the relationship between food habits and satellite television preference in South-West Nigeria.

ii. Find out the relationship between customs and satellite television preference in SouthWest Nigeria.

iii. Examine the relationship that exists between belief and satellite television preference in South-West Nigeria.

iv. Examine the relationship between belief and satellite television preference in SouthWest Nigeria.

\section{Research Questions}

i. What is the relationship between food habits and satellite television preference in South-West Nigeria?

ii.What is the relationship between customs and satellite television preference in South-West Nigeria?

iii. What is the relationship that exist between belief and satellite television preference in SouthWest Nigeria?

iv. What is the relationship that exist between belief and satellite television preference in SouthWest Nigeria?

\section{Research Hypothesis}

Ho: There is no significant relationship between food habits, customs, beliefs, morals and satellite television preference in South-Western states of Nigeria.

\section{REVIEW OF RELATED LITERATURE}

\section{Culture}

Culture has been defined differently by different people. The different definitions attached to culture are based on the differences in the orientation of their originators. The concept of culture consists of the values the members of a given group hold, the norms they follow, and the material goods they create. It refers to the full range of human behaviour that make up the way 
of life of the individual member or groups within a society; how they dress, their language, beliefs, values and norms, customs, dress, diet, roles, knowledge, skills and leisure pursuits. Accordingly, Ekeh (1989), in Yusuf (2000), subscribes that culture is a construct used in an attempt to analyse and integrate events and ideas in broad spectrum of areas of society. It is for this reason that Jekayinfa (2002), in Yusuf, states that "from wider perspective, culture includes the total repertoire of human action which are socially transmitted from generation to generation". Kanagy and Kraybill (1999), in Oni (2005), described culture as "set of tangible and intangible elements - things like diet, tools, technology, language and values - that gives shape and meaning to everyday lives of a particularly group of people".

The legacy of a people lies in their heritage, handed over to them on successive notes from generation to generation. The people of Africa in support to the fore statement do have it at their forebear to at all times respect and preserve their heritage which forms a great deal of their cultural values. On this note, culture, as seen as the legacy of the African man is tenaciously held to and on a continuum, handed over to subsequent generations for the purpose of sustainability, with the youth population seen as key to its possibility. This can be depicted in a maxim that states "our culture our pride". The culture of the African man is seen as his pride, thus, any danger that portends toward it is looked upon as a slap and derogation on the African's man pride. It is in this light that our statement of problem posited a paradox, in trying to see technological development and globalization as having a two faces on the same coin, with one positing "good" and the other "harm". It is in this vein that Patricia (2013) posited that "the character of the mass media is such that it is expected to bring about positive influence in the lives of its audience through contents that lend credence among other things to the preservation of the culture and intrinsic values of the society' The concept of culture has also been viewed as the rich complex of meanings, beliefs, practices, symbols, norms, and values prevalent among people in a society. The prevailing value in a society may be the most central feature of culture (Hofstede, 1980; Inglehart, 1997; Schwartz, 1999; Weber, 1958; Williams, 1968). These values are shared conceptions of what is good and desirable in the culture and the cultural ideals.

Cultural value shape and justify individual and group beliefs, actions, and goals. Institutional arrangements and policies, norms, and every day practices express underlying cultural value in societies. For example, a cultural value emphasis on success and ambition may be reflected in and promote highly competitive economic systems, confrontational legal systems, and childrearing practices that pressure children to achieve. The preference element in cultural value orientations - values as ideals - promotes coherence among the various aspects of culture. Since prevailing cultural value orientations represent ideals aspects of culture that are incompatible with them, they are likely to generate tension and to elicit criticism and pressure to change.

\section{Characteristics of Culture}

Samovar et al. (2010) stated six (6) features of culture and they are:

(a) Culture is an integrated system. It has several components all put into one. Those components are called its elements and they include language, dress pattern, ideas, dance steps, food, religion, norms, and values and among others.

(b) Culture is diverse. This explains the reason why there are numerous cultural systems in the world all over and leading to both relativity and conflict. 
(c) Culture is shared. This implies the cause of culture exemplifying "social inheritance". It is handed down from one generation to another and made meaningful and intelligibly acceptable to other members of the society.

(d) Culture is encoded in symbols. Cultural symbols could be its elements. They are vehicles through which the culture of people is represented and codified.

(e) Culture is transmitted from one generation to another. This is made vivid in the words of Samovar and Porter (2004) that "all the past is here". This makes a role for sustainability where culture is preserved and survives into the future.

(f) Culture is learned. The process by which culture is learned and taught is called enculturation". Culture is learned through observation, imitation, and interaction. It is at this point that functions of the mass media cannot be overruled.

\section{Cultural Value Orientations}

Cultural value orientations evolve as societies confront basic issues or problems in regulating human activity. People must recognize these problems, plan responses to them, and motivate one another to cope with them. The ways that societies respond to these basic issues or problems can be used to identify dimensions on which cultures may differ from one another. The cultural value orientations at the poles of these dimensions are Weberian ideal-types. The theorist derived value dimensions for comparing cultures by considering three of the critical issues that confront all societies. First issue is the nature of the relation or the boundaries between the person and the group: To what extent are people autonomous vs. embedded in their groups? This is labeled as the polar locations on this cultural dimension autonomy versus embeddedness. In autonomy cultures, people are viewed as autonomous, bounded entities. They should cultivate and express their own preferences, feelings, ideas, and abilities, and find meaning in their own uniqueness. There are two types of autonomy:

Intellectual autonomy encourages individuals to pursue their own ideas and intellectual directions independently. Examples of important values in such cultures include broadmindedness, curiosity, and creativity.

Affective autonomy encourages individuals to pursue affectively positive experience for themselves. Important values include pleasure, exciting life, and varied life.In cultures with an emphasis on embeddedness, people are viewed as entities embedded in the collectivity. Meaning that life comes largely through social relationships, through identifying with the group, participating in its shared way of life, and striving toward its shared goals. Embedded cultures emphasize maintaining the status quo and restraining actions that might disrupt ingroup solidarity or the traditional order. Important values in such cultures are social order, respect for tradition, security, obedience, and wisdom.

The second societal problem is to guarantee that people behave in a responsible manner that preserves the social fabric. That is, people must engage in the productive work necessary to maintain society rather than compete destructively or withhold their efforts. People must be induced to consider the welfare of others, to coordinate with them, and thereby manage their unavoidable interdependencies. The polar solution labeled cultural egalitarianism seeks to induce people to recognize one another as moral equals who share basic interests as human beings. People are socialized to internalize a commitment to cooperate and to feel concern for everyone's welfare. They are expected to act for the benefit of others as a matter of choice. 
Important values in such cultures include equality, social justice, responsibility, help, and honesty. The polar alternative labeled cultural hierarchy relies on hierarchical systems of ascribed roles to insure responsible, productive behavior. It defines the unequal distribution of power, roles, and resources as legitimate. People are socialized to take the hierarchical distribution of roles for granted and to comply with the obligations and rules attached to their roles. Values like social power, authority, humility, and wealth are highly important in hierarchical cultures.

The third societal problem is to regulate how people manage their relations to the natural and social world. The cultural response to this problem labeled harmony emphasizes fitting into the world as it is, trying to understand and appreciate rather than to change, direct, or to exploit. Important values in harmony cultures include world at peace, unity with nature, and protecting the environment. Mastery is the polar cultural response to this problem. It encourages active self-assertion in order to master, direct, and change the natural and social environment to attain group or personal goals. Values such as ambition, success, daring, and competence are especially important in mastery cultures. In sum, the theory specifies three bipolar dimensions of culture that represent alternative resolutions to each of three problems that confront all societies: embeddedness versus autonomy, hierarchy versus egalitarianism, and mastery versus harmony.

\section{Features of Cultural Value Orientations}

Cultural value orientations are not fully coherent: In a society whose cultural value orientations emphasize collective responsibility, for example, a firm that fires long-term employees in the interests of profitability is likely to elicit widespread criticism and pressure to change policies. In addition to a dominant culture, subgroups within societies espouse conflicting value emphases. The dominant cultural orientation changes in response to shifting power relations among these subgroups. But change is slow.

Another important feature of cultural value orientations is that they are relatively stable (Hofstede, 2001; Schwartz, Bardi and Bianchi, 2000). Some researchers argue that elements of culture persist over hundreds of years (e.g., Kohn and Schooler, 1983; Putnam, 1993). Yet, cultural value orientations do change gradually. Societal adaptation to epidemics, technological advances, increasing wealth, contact with other cultures, and other exogenous factors leads to changes in cultural value emphases. Culture joins with social structure, history, demography, and ecology in complex reciprocal relations that influence every aspect of how we live.

Cultural value is difficult to measure: To reveal the cultural orientations in a society, we could look at the themes of children's stories, at the systems of law, at the ways economic exchange is organized, or at socialization practices. These indirect indexes of underlying orientations in the prevailing culture each describe a narrow aspect of the culture. When researchers try to identify culture by studying the literature of a society or its legal, economic, family, or governance systems, what they seek, implicitly or explicitly, are underlying value emphases (Weber, 1958 and Williams, 1968). Therefore, studying value emphases directly is an especially efficient way to capture and characterize cultures. 


\section{Satellite Television: An Overview}

Television as an electronic medium has indubitably transformed the media and its main traditional functions of information, education, entertainment and correlation of the society. There is no gainsaying that today, television has become a part of everyday life which was not so between the 1920s when it was invented and the 1960s when it lost its novelty. As a result of commercialization, the number of television stations have greatly increased, so also the number of television sets available in homes.

Television is an inescapable part of modern culture. One depends on television for entertainment, news, education, culture, weather sports and even music, since the advent of music videos. With the recent explosion in Satellite and digital specialty channels, there is now access to a plethora of both good quality and inappropriate television content. Television is an electronic device which transmits picture and sound. Television combines the appealing feature of the movies and radio and is one of the most popular amusements during the childhood's years. It lures children away from other forms of play. Many babies are introduced to television while they are still in their cribs. For them, television is a built-in baby sitter because it keeps them amused when no one is available to act in this role. For the preschool child and even the older child, television watching is an added play activity, though, not a substitute for active play and other forms of passive play, but for many children it is more popular and more consuming of their play time than all other play activities. Television is still an important medium for children and they use it actively. However, while children regard it primarily as a source of entertainment (Livingstone, 2002), many parents often see it, particularly for young children, as an important educational tool that can assist children intellectual development (Rideout, 2003).

Television can be of benefit to children. It can bring them into contact with aspects of life they would not otherwise become aware of. It can provide a valuable tool in the home and at school not simply to get children occupied but also as a constructive way to use their time. It is a channel through which a range of entertainment, drama and learning can be obtained and experienced and increasingly these days it is under the control of the viewer (Gunter and McAleer, 1997). According to Signorielli and Michael (2001), television is still the most popular medium, occupying a significant proportion of children's time, up to 13.9 hours a week, with higher viewing for those from ethnic minority (15.2 hours) and low income groups (15.5 hours).

The growth of television globally over the last two decades has been extraordinary. Statistics reveal that more than 95 per cent of households in America own at least one TELEVISION set and on an average, television occupies about seven hours a day in those households which translates into 2,400 hours per year - the most consuming activity besides sleep, (Wilson and Wilson, 2001; Dominick, 2005; Vivian, 2009). The medium has been of tremendous influence whether positive or negative as it has changed the way we socialize across all strata in the society. Novak (1998), in Vivian (2009), comments that television is "a molder of the soul's geography. It builds up incrementally a psychic structure of expectations. It does so in much the same way that school lessons slowly, over the years, tutor the unformed mind and teach it how to think." Corroborating, Comstock, also in Vivian submits that "television has become an unavoidable and unremitting factor in shaping what we are and what we will become (2009)". 
International Journal of Business and Management Review

Vol.8, No.2, pp.1-36, March 2020

Published by ECRTD-UK

Print ISSN: 2052-6393(Print), Online ISSN: 2052-6407(Online)

\section{Theoretical Framework}

This study is hinged on cultivation theory and social learning theory developed by Gerbner (1977) and Bandura (1997) respectively.

\section{Cultivation Theory}

Cultivation theory proposes that repetitive or persistent consumption of certain media content leads to change of attitude, values and adoption. The theory, according to its proponent suggests that mass media, especially Satellite television, is responsible for molding viewers' perception of social reality. Analyzing the theory, Anaeto et al. (2008) emphasized that television has a cultural function of socialization and acculturation; television indirectly exposes certain ideas and knowledge one would not have ordinarily known. As it relates to this study, it implies that the abandonment of local media contenting television airwaves gradually results to diminishing of values, beliefs and norms. With the proliferation of westernized media contents, Nigerians have adopted a different social relationship away from what was traditionally obtainable in our norms and values; this may grossly affect the assimilation of culture in the Nation.

\section{Social Learning Theory}

Social learning theory proposed by Bandura (1997) argues that observers can acquire symbolic representation of behaviours and this picture provides information on which to base subsequent behaviour. Social learning involves both imitation and identification to explain how people learn through observation. Imitation is the reproduction of observed behaviour. Identification on the other hand is a form of imitation that springs from wanting to be and trying to be like an observed model relative to some characteristics or qualities (Bandura, 1997).

This theory is generally applicable to socializing effects of media and the adoption of various models of action. Therefore it applies to everyday matters such as clothing, appearance, style, eating and drinking modes of interaction. McQuail (2005) and Harrison and Cantor (1997) cited in Aneto, Onabajo and Osifeso (2008) however applied the social learning theory to examine the role of television in influencing audience members' ideas about thinness and ideal body shape. The researchers noted that images of thinness and dieting are very common in the mass media and the mass media often provide instances of thin actors being rewarded. They found out that viewers with higher exposure to messages about thinness had a tendency to have a high drive or desire to become thin and dissatisfied with their bodies.

In relation to this study, this theory seems to explain the food /eating habits of Nigerian youths as it relates with the values depicted in western programmes. What is largely portrayed in western television programmes is that thinness is part of beauty. Young girls who are not thin are far more likely to feel ashamed and distressed by the changes in their body and appearance. They can become more insecure and self-aware of the changes that occur. Therefore, many Nigerian youths especially women can become dissatisfied with their body shapes to the extent that they go on starving themselves under the disguise of losing weight just to be skinny like the characters they see on television. The central argument of the cultivation analysis theory as proposed by Gerbner and his colleagues in Baran and Davis (2003) is that television creates a worldview that although possibly inaccurate, becomes the reality simply because people believe it to be the reality and they base their judgment about the everyday world on that "reality". McQuail (2005) citing Gerbner (1967) says that television is responsible for a major cultivation and acculturating process according to which people are exposed systematically to 
International Journal of Business and Management Review

Vol.8, No.2, pp.1-36, March 2020

Published by ECRTD-UK

Print ISSN: 2052-6393(Print), Online ISSN: 2052-6407(Online)

a selective view of society on almost every aspect of life, a view which tends to shape their views and beliefs.

\section{Empirical Review}

Akintayo and Adegoke (2015) carried out a study on Western entertainment television programmes: a catalyst for behavioural tendencies among students of Babcock and Covenant Universities. This study probed the influence of Western entertainment television programmes on the behaviour of Nigerian youths. Using the survey method, and questionnaire as instrument; a total of 300 students from Babcock University, and Covenant University were selected. Findings revealed that Western entertainment television programmes influenced the style of dressing of Nigerian youths, sexual behaviour and food habits .Also that youths exhibit violent behaviours, imitate foreign accent and engage in public display of affection as a result of watching Western entertainment programmes. It was recommended that programme producers should be more creative and original in the production of indigenous programmes, reduce the emphasis placed on body shape, and that parents should help reduce amount of sexual and violent content they expose their wards to at home by having family programmes viewing time.

Chinenye, Nnamdi, Loveth, and Emelda (2012) studied Satellite television and local media use among viewers in Satellite Television households in the Southeast geopolitical zone of Nigeria. The basic objective of the study was to examine the influence of Satellite television broadcasting on local media use among viewers in Satellite television households in the southeast geopolitical zone of Nigeria. The study adopted the survey research method in studying a sample size of 384 respondents. Among the null hypotheses tested in the study was that there is no significant difference between the level of exposure to Satellite Television and Local Television by viewers in Satellite Television households, and there is no significant relationship between age and level of exposure to Satellite Television among viewers in Satellite Television households. The study revealed among others that viewers in Satellite Television households tend to watch more Satellite Television than local Television basically due to high quality programme production, and a variety of exciting programmes offered by the Satellite Television channels, though the difference in exposure level was not significant. It was recommended among others that broadcast media houses in Nigeria should strive to improve programme content and production quality with a view to competing effectively with foreign channels.

Ahmed, Pawanteh, and Rahim (2012) conducted a study to examine if the sexual image that young people watch on television influences their attitude towards sexuality and how young people perceived issues and images of sexuality on television and how they try to reconcile with cultural norms and cultural expectations. The finding from the analysis of the images on sexuality in media channels (television) consumed by young people in Kuala Lumpur and Selangor. All participants for this research were selected through purposive sampling to ensure there is an element of homogeneity. A total of 4 focus group discussions were conducted. Each focus group consists of five to six young people whose age are between 18-24, with a combination of two males and three females or three males and two females. The result shows that young people in Malaysia relied on mass media, especially the television, to get information on intimate human relations concerning sexual information as sexual education at schools was minimal. if any. to a certain extent in providing knowledge on sexual lifestyle. 
Research results revealed that matters pertaining to sexuality are discussed with friends of the same sex. Most young people in Malaysia grew up in households where parents do not feel it is appropriate to show affection, even kissing and hugging. This research results revealed that young people's view on the portrayal of sexual images on television influences their attitudes towards sexuality.

Salman, Muhammad and Asghar (2014) studied analysis of Pakistan Television Corporation entertainment programs and its effects on youth. The study was conducted to examine and indicate the consumption patterns of Pakistan Television Corporation (PTELEVISION) entertainment programs of rural viewers of Karor Lal Eason (Layyah). The objectives among others include; to explore the consumption patterns of PTV entertainment programs by the rural viewers, to dig out purpose of watching PTV entertainment programs, to determine the extent of liking in the PTV entertainment programs by the rural viewers and to find out the effects of the PTV entertainment programs on the rural youth and their daily routine activities.

To meet the requirements of the study, stratified method for specification of the viewers' characteristics was adopted and convenience method was used for collection of data from the target population. Due to resource and time constraints it was not possible for the researchers to collect data from the large population of tehsil Karor. Total of 200 respondents were selected which includes 100 male and 100 female viewers of PTV. Babbie (1992) stated that "This practice has the effect of improving the representation of a sample by reducing the degree of sample error". According to Selltez et al. (1976) "Population is divided into two or more strata in stratified method. This procedure generated and organized population into homogeneous subsets and selected various elements from each". Travers (1978) stated that that "Major advantage of this procedure is that it increases accuracy". According to the requirements of present study pre test was conducted .Its basic objective was to understand the problems in the questionnaire and to overcome the weakness.

The findings indicated that the viewers preferred to watch PTV entertainment programs and they also spend maximum time on watching entertainment programs of PTV. It was indicated that most of the respondents preferred to watch the PTVentertainment programs during prime time. Findings further indicated that female viewers change their working time to watch their favorite programs which includes dramas. Findings show that most of the respondents express their views that PTV entertainment programs are promoting new cultural trends in the rural society. The findings revealed that most of the respondents agreed that the PTV entertainment programs were helpful for them to adopt new cultural trends, in the same way it was the perception of overall respondents that new cultural trends presented in the PTV entertainment programs should come to their traditional society.

Robaka \& Mohammad (2012) examined the effect of Satellite Television on the culture of Bangladesh: the viewers perception. The main purpose of the study is to understand the effects of Satellite Television on the culture of Bangladesh. The study, specifically wanted to find out the consumers attitude towards Satellite television, the demand of various Satellite channels based on consumer profile, the satisfaction level of general consumers based on the existing service provided and to understand the effects of Satellite channel on the indigenous culture mainly from the consumers point of view. 
The methodology used for this study included both primary and secondary data collection. Some of the historical data were taken from the secondary sources. In reviewing the literature for collecting the secondary data, both theoretical and empirical studies were taken into consideration. Secondary data were collected through content analysis from various published sources including books, online journals, newspapers, magazines, and reports. For developing the questionnaire and selecting the sample personal experience and observation was used. The target population of this study was the people of Chittagong city who have television and possess cable connection in their houses. Any one staying in mess/ hostel but having cable television facilities were also part of the target population of the study. To carry out the survey, non- probability judgmental sampling was used. As there was no comprehensive list of the population of Chittagong city, hence conducting the probability sampling was not feasible and in an attempt to get a general representation of the population total of 3 major areas of interest was selected using the judgmental method. The areas were Khulshi, Jamal Khan and Chittagong Port Area which represented three different classes of people. In Khulshi the higher Class people, in Jamal Khan the middle Class and in Chittagong Port Area generally the Lower Middle Class reside. No specific sampling frame is available. The respondents within the specific area were also selected on judgmental basis. The sample size was 40 and efforts have been taken to include both males and females and consideration was also given for different age groups.

Findings from the study showed that the satisfaction level of the consumers about the existing service provided by the cable operator in terms of number of channels, picture quality, sound reception and monthly payment was high. This shows that consumers, in general, are satisfied with the existing service. There are no significant changes in the consumers' opinion as a result of the demographic classification. More than $85 \%$ of consumers were satisfied with the quality of picture and sound. About $25 \%$ of consumers think that numbers of channels are not sufficient. As the monthly charge came into the picture, an interesting relationship was found. Only $35 \%$ of the respondents thought that the monthly charge was high and they were the people who are somehow related to the payment. The younger people, i.e those whose money was not used for payment thought that the monthly charge was reasonable. Also Consumers have a positive attitude towards the Cable channel. $37.5 \%$ of the consumers think it to be a means for increasing knowledge and education along with recreation. $27.5 \%$ think it only as a means of recreation, $30 \%$ thinks it as a means for increasing knowledge and education whereas $17.5 \%$ think of as it just a means for passing time. It was discovered that people prefer watching TELEVISION after the evening than during the day time. Within the night, the most preferred time is 8:30-11:30 pm. In addition some people also prefer the day time especially after lunch hour i.e. 1:00-03:30 pm.

The respondents of the survey are on a common footing about their opinion in relation to the means of exposure to foreign culture. $95 \%$ of the respondents think that cable TELEVISION is the main reason for the exposure to the foreign culture as it is the most available and easy means that one can get within their surroundings aside other means like internet, newspaper/magazines.

Elaheh and Afsaneh (2014) conducted a study on the impact of Satellite Television channels (GEM, P.M.C. and Manoto) on lifestyle changes for women in Tehrah, Iran. Objectives include; to studying lifestyle changes patterns induced by Persian Satellite networks with an 
emphasis on the target population (women), identifying and understanding the impact of Satellite Television channels on Iranian women in various cultural and social spheres and explaining the philosophical foundations of the Satellite Television channels and its impact on the lifestyle of women.

The study made use of a descriptive survey method. However, in this study, a mixed method was applied. Using "Delphi method", Comments of experts in the field of culture and communication and philosophical principles and characteristics of each of Satellite Television channels and their impact on the kind of lifestyle have been asked in deep interviews, and then the lifestyle factors already affecting women was discussed. By setting questionnaire and conducting survey, the impact of Satellite Television channels on the lifestyle changes for women in Tehran was studied. Lastly, two methods of Delphi and survey were applied to collect data and the Pearson correlation coefficient was used to analyze the data and test the research hypotheses.

The overall findings of this study with respect to the propositions derived from the responses of the respondents and analysis of questionnaires showed that, there is a significant relationship between lifestyle changing patterns applied in all three Satellite Television channels of (Manoto, GEM and P.M.C) and lifestyle changes style of women in Tehran. Also, a pattern of lifestyle changes imposed by the Channel of Manoto is most correlated with the lifestyle changes style for women in Tehran. It was discovered that patterns of lifestyle changes imposed by P.M.C. channel had the lowest correlation with quality of lifestyle changes of women in Tehran. Lastly, the relationship between patterns of lifestyle changes applied on all three channels of Manoto, GEM and P.M.C. and the lifestyle change styles for women in Tehran is straight i.e. the more the lifestyle changes pattern are applied, the more lifestyle changes for women in Tehran. Given the foregoing discussion, the main hypothesis of this study is confirmed and it was concluded that Persian -language Satellite channels seek for a change in lifestyle among Iranian women.

Garba (2015) investigated the influence of home television viewing on academic achievement of children in upper basic education in Kaduna state, Nigeria. The study aimed to investigate the influence of home television viewing on academic achievement of children in upper Basic Education Level in Kaduna State. The study established the influence of televisions viewing on the pupils' language development and achievement in basic science. The study also determines the influence of televisions viewing on pupils' numeracy development and achievement in social studies. The study was guided by four research questions and four formulated null hypotheses tested at 0.05 level of probability.

The design of the study was an ex-post facto survey design. The area of the study was Kaduna State of Nigeria. The population of the study consisted of all the children in the upper basic level of education in schools in Kaduna State. Multistage and stratified random sampling techniques were used in selecting the 320 pupils that were used for the study. A researcherdeveloped instrument called 'pupils television viewing identification questionnaire' (PTVQ). The instrument was face validated by three experts in the department of vocational Teacher education, University of Nigeria, Nsukka. The internal consistency reliability coefficient obtained using Cronbach alpha method was 0.67. Data were collected by recording the continuous assessment scores of pupils on Mathematics, English languages, Basic Science and 
Social Studies. The data collected were analyzed using mean and standard deviation to answer the research questions while t-test analysis was used in testing the null hypotheses at 0.05 level of significance.

The findings of the study included: that home television viewers scored higher than the nontelevision viewers on Basic English continuous assessment tests; the home television viewers scored higher than the non-television viewers on basic Mathematics; at $\mathrm{p}<0.05$, there was a significant difference between the mean scores of home television viewers and non-television viewers on Social Studies tests. It was recommended that the viewing of television in homes and schools especially on academic activities should be encouraged by parents and teachers to enhance pupils learning.

Apuke and Dogari (2017) studied Western television program and its influences on the cultural values of students in Taraba State University, Jalingo, Nigeria. Their study explored the situations surrounding the relationship between Western Television Programmes and the cultural values of the Nigerian youth population, with particular reference to Taraba State University where constructive generalizations were made. Findings were backed-up with an empirical research on 145 respondents from the study area. Cross-sectional Survey design was adopted for this work. The bottle spinning sample technique was used alongside availability/convenient sampling technique. The study also made used of the questionnaire as a means of quantitative data collection. The SPSS (Statistical Packages for Social Sciences) was employed for data analysis and subsequently justified using manual procedures. Six (6) research questions were utilized in empirically justifying the work. Finally, the study discovered that Nigerian Youth prefers viewing WTP more to indigenous television programmes and this exerts great influence on their cultural values. The study recommends that in salvaging the undue influence vented on the cultural values of youth by Western Television Programmes, there is the need for a constant review of the schooling content of the Nigerian education system, such that its culture would be lucidly pronounced.

Yannis, Georgia, Katerina and Thodoris (2009) conducted a study on factors associated with television viewing time in toddlers and pre-schoolers in Greece. The broad aim was to describe the television viewing time of preschoolers and to examine factors that may be associated with it. The study used the descriptive design and a representative sample of 2374 Greek children, aged 1-5 years was examined. These children were enrolled from a representative sample of randomly selected public and private nurseries as well as day care centres within municipalities in five countries of Greece namely; Attica, Thessalonica, Halkidiki, Aitoloakarnania and Helia. Attica and Thessalonica were chosen because they cover the largest part of Greek population (almost 60\%) and the rest three because they were convenient counties. All nurseries invited to participate responded positively and then took part in the study. Among the total number of nursery school studied $(\mathrm{n}=115), 65$ were in Attica, 10 were in Thessalonica, 12 were in Halkidiki, 22 were in Aitoloakarnania and 8 were in Helia.

The sampling of the nurseries was random, multistage and stratified by the total population of the children. After final sampling, a complete data for 2374 children was available for study. The research instruments used for the study were questionnaire and structured interview. Normality of distribution was evaluated through the Shapiro-wilk test. Continuous variables were presented as mean, standard derivation (SD) and categorical variables were summarized 
as relative frequencies $(\%)$. Associations between categorical variables were tested by use of contingency tables and the calculation of chi-square tests without the correction continuity, because the television viewing time was not found to be normally distributed $(\mathrm{P}<0.001)$, the associations between this viewing time and other categorical characteristics were evaluated through Mann-whitney or krustal-wallis test, as appropriate correlations between children's television viewing time and other continuous characteristics (parents' television viewing time and time that parents spent with their children) were also assessed using spearman correlation coefficient. A probability value of $5 \%$ was considered as statistically significant.

The finding of the study revealed that the mean value of children's television viewing time was 1.32 (1.12) hours per day. Twenty six percent of participants spent 2 hours per day and more watching television (i.e $22.9 \%$ spent $2-4$ hours per day and only $3.1 \%$ spent more than 4 hours per day in front of a television set). The percentage of children whose television viewing time was lower than 2 hours per day was higher in children aged 3-5 years $(32.2 \%)$ than in children aged 1-2 years (11.1\%) and no significant difference was observed between boys and girls. The mean value of parents' television viewing time was almost 2 hours per day for both mothers and fathers. In particular, 55\% of fathers and $44 \%$ of mothers spent more than 2 hours per day in watching television. In addition, only $9 \%$ and $7 \%$ of fathers and mothers respectively spent 4 hours per day and more. The study examined the television viewing period by different age category of children. However, in the present study, the influence of home television viewing on children's academic achievement will be determined. Also, frequencies were used in data analysis of the previous study but in the present study, mean, standard deviation and t-test was adopted in data analysis.

Enna (1994) conducted a study on the effect of violent television programmes on the attitude of adolescents towards violence. The study was carried out in plateau state, Nigeria. The aim of the study was to investigate if there was an effect of television violence on the attitude of the adolescence among secondary school student in some major towns of plateau state, and also to find out teachers and parents' opinion about the effect.

The research design was survey method of descriptive research. The sample size comprised forty (40) students, from each of the five schools selected making a total of two hundred (200) students. Twenty (20) Teachers and parents were selected from each of the five (5) schools in five (5) local government areas making a total of one hundred (100) teachers and parents. The total sample size was three hundred (300) made up of student, parents and teachers who were randomly selected. The research instrument used for the data collection was the questionnaire. There were 30 items questionnaire for the students and 20 items questionnaire for teachers and parents. Descriptive statistics, tallies, frequency tables and percentages were used to identify the perception of the respondents.

The finding of the study showed that forty-nine percent (49\%) of the adolescent view television for 4 hours daily. $73.5 \%$ of the adolescent prefer wrestling because they love the violence displayed in it. 53\% love educational programmes. $76.6 \%$ of the teachers and $94.1 \%$ of the parents agreed that violent television programmes has a positive effect on the attitude of adolescent towards violence that is, the adolescent learn skills which they use in vandalism, destructiveness and aggression from television. $57.4 \%$ of teachers and $62.5 \%$ of the parents 
wanted television violence to be reduced. $67.5 \%$ of the adolescent found violent television programme enjoyable.

Stanislaus (2014) studied global television and cultural promotion: taming the cultural dilemma among nigerian youths. The study was conducted to re-examine the impact of global television on the behavior of youths in Nigeria. It identifies cultural imperialism as the most significant impact of global television achieved through programs like sports, drama, musicals, and violent movies transmitted to Nigeria and other third world nations. These programs are transmitted under the guise of informative, educational and entertainment programs while the Nigerian youths are the most affected victims. Through careful analysis of previous researches and literatures, the study posits that Nigerian youths are caught between the dilemma of the foreign cultures and their indigenous cultures in terms of dress codes, speech, dance and the general ideologies.

Also, most Nigerian youths are affected by the accent and language of the pop stars, actors and actresses and the characters in the advert the watch on the global television. Girls are accepting being called "bitch" (a female dog). The youth copy suggestive dance steps, nude modes of dressing, and images that incite young men and women. Most youths copy violent behavior from what they view on global television. They learn how to be unnecessarily aggressive. In addition they prefer to watch the European league to the detriment of their own local league. No more "tales by moonlight" as parents also retire early to bed after a hard day's job.

Nigerian ladies prefer foreign creams, soaps and cosmetics to the local counterparts. In Nigeria, the youths are young persons of between childhood age and the period before adulthood. They are the majority dependants on their parents for food, clothing and shelter. They are the most idle and unemployed persons who depend on any available information to satisfy their insatiable quest for knowledge that would prepare them for life in future. They depend on local and global media especially television and the internet because of their features of visual, audio, motion and easy accessibility. Their continuous patronage of global television programs have robbed majority of the Nigerian youths of the Nigerian culture. The Nigerian youths have adopted foreign cultures in forms of manners of speaking, dressing, acting, behaving, eating, loving, thinking, dancing, singing and more.

The study concludes that aggressive cultural communication and government's programs targeted at youths at all levels are one of the suggestions that can help tame the cultural dilemma among the youth. It was recommended that the local television stations should increase the hours for transmitting knowledge-driven programs on Nigerian cultures. The programs should be participatory, competitive and rewarding. The Nigerian Broadcasting Corporation (NBC) should ban global television programs with corrupt contents of nudity and violence without discouraging entertainment programs like foreign sports. Drama series and adverts that possess corrupt tendencies and pose a threat to the Nigerian cultures should be banned from the Nigerian airwaves. Finally, the Federal Government of Nigeria should be involved in youth development agenda through the agents of socialization.

Nekmahmud and Ferdush (2016) investigated the audience attitude towards satellite TV programs and advertising in Bangladesh and also examined the program preference of the audience. The study is descriptive in nature. To conduct the research, primary and secondary 
data sources of information were used. The study has been conducted among 505 respondents which included the seven (7) categories of audiences on the different geographical location of Bangladesh.

The study helps the program producer to find out when audiences prefer watching the advertising and which programs are the most preferable for advertising. The selected population included seven (7) types of audiences like Student, Service holder, Business, Retirement job holder, Farmer, Household and Day labor or Rickshaw puller on the different geographic location of the Rangpur Division in Bangladesh. The random sampling method is used to select television audience from eight (8) district likes Rangpur, Sador, Kurigram, Lalmonirhat, Nilfamari, Ponchogor, Thakurgao and Dinajpur district under Rangpur divisions in Bangladesh. Primary data were gathered more than five (5) month period frame amid the January to May, 2016. The questionnaires were distributed specifically to the gathering of people as a study test. In this study, researchers distribute 700 questionnaires to the audience for measuring behaviour towards satellite television programs and advertising in Bangladesh. Among them, 600 respondents gave back the topped off questionnaires. Because of respondent's failure, unconsciousness and over the top missing qualities, 95 questionnaires were dropped. In this way, at last the span of the specimen remains at 505 (five hundred five). The study is quantitative and descriptive in nature and is conducted based on primary and secondary data.

The result of the study shows that 90.9 percent of audiences watched private satellite television channels. 20.0 percent of audiences are interested to see more television programs on Indian Bangla channels. 36.0 percent of audiences preferred watching news and drama in Bangladeshi television channels. 40.7 percent of Bangladeshi people preferred watching movies on Indian television channels. It was also revealed that 27.1 percent of audiences are avoiding the advertising at the time of telecasting the television programs, but 46.3 percent of the audiences prefer to see more advertising in the middle of the program. 64.6 percent audience believed that Bangladeshi satellite televion channels broadcast has the standard qualities of advertising.

Michael, (2015) investigated the determinants of the demand for cable television services in the era of ICTs. The main objective is to identify the relationship between cable television and VOD substitute services at the aggregate national level as well as identify some of the mechanisms behind this relationship. It was an observational study using a sample of the U.S. quarterly national-level data for years 2008-2015. The data on the number of Time Warner Cable (TWC) subscribers was used as a proxy for cable television consumption, while the data on the number of Netflix subscribers was used as a proxy for VOD services consumption. Several specifications of the OLS regressions were estimated for controlling local price, availability of related goods (VOD services, mobile phones, Internet), and income.

The results contributed to the existing literature on the economics of entertainment by presenting evidence of substitution between the VOD services and cable TV services. More specifically, the estimates for the elasticity between TV and VOD services, obtained using firstdifferences OLS estimation, suggest that a 1 percent increase in the number of Netflix subscribers is associated with a 0.123 percent decrease in the number of TWC subscribers. This implies that providers are likely to benefit from focusing on offering extra value to consumers rather than trying to gain additional revenue through advertising. The results of the analysis 
also highlight that higher prices for cable TV services are likely to be interpreted by consumers as a signal for quality. More specifically, the estimates suggest that a 1 percent increase in local price is associated with 0.38 percent increase in the number of TWC subscribers. This implies that offering greater choice of programs and higher subscription prices might be the pricing strategy to increase revenues. The findings provide a better understanding of the mechanisms behind consumer choice and decision-making processes. In turn, this understanding elicits valuable insights into television programming services revenue sustainability, and the competition of the providers of these services with the providers of the VOD services.

Jaume and Placido (2006) investigated the determinants of television audience for Spanish football: A first approach. Their study focused on the analysis of the determinants of the size of the audience for Spanish First Division football games. It followed the same approach as Forrest et al (2005) when analysing the same issue for the English Premier League. Two models were estimated; one for the broadcaster's choice of the match to be televised and another one for the size of the audience, distinguishing between public and private broadcasters. Report on some evidence showing how broadcasting affects the financial structure of the clubs and the competitive balance of the league and also showing the evolution and distribution between clubs and the size of the audience. The study reviewed the demand literature for professional sports with special attention to the effect of televising matches on live attendance and to the modelling of the size of the audience. The research also showcased explanatory variables which try to capture the demand determinants for professional sports: ex-ante attractiveness of the match, recent performance (including outcome uncertainty), variables capturing the television appearances of the teams and sometime variables, capturing the long run trend and some seasonal (within season) effects. Available evidences were presented to show how important these groups of variables are in explaining the choices of the broadcasters and the size of the audience. In this sense, this study is complementary to a previous one analysing the determinants of live attendance in the Spanish football

The study as earlier mentioned follow Forrest et al (2005) by modelling both the determinants of the broadcaster's choice of a match and of the audience for the matches of the Spanish First Division Football League. Consequently, estimating both equations for each of the broadcasters. The sample is composed of those matches played (and televised in the case of the audience equations) during the seasons 2000-01, 2001-02 and the first part of the 2002-03 season. The study modelled each broadcaster's (FORTA and Canal+) choice by means of a Probit model, including three potential types of explanatory variables. When comparing the results for both broadcasters, substantial differences in the effects of the explanatory variables were discovered. In both models the variable which captures teams' joint quality (sum of relative spending) has a significant positive effect on the probability of a match being chosen by the broadcaster, the effect being stronger for the FORTA model. Increasing the variable by one makes the probability of choosing a match by more than $56 \%$ in the case of FORTA and by more than $30 \%$ in the case of Canal + . The effect does not change very much depending on the way the recent performance of the teams were specified. On the other hand, when looking at the other estimated coefficients for the variables in this group, some important differences could be observed.. The condition of a match being a derby has a positive significant effect on the probability of broadcasting a match in the case of FORTA but, although positive, the effect is not significant for Canal +. The same type of result is obtained for the estimated coefficient of the variable capturing the ex-ante quality closeness of the teams (difference in relative 
spending), which has, as expected, a negative effect on the probability of broadcasting a match in FORTA, but the effect, although negative, is almost negligible in the case of Canal + .

Finally, the variable trying to capture the effect of the market size has a significant positive effect on Canal + choices, but not in the case of FORTA. This can be explained by the different economic objective functions which are faced by both broadcasters. In the case of Canal + , if they try to maximize profits then the number of the potential viewers, since they are fans of one the teams playing the match, should matter when choosing the match, whereas in the case of FORTA, as an association of the regional public channels, the choices are made in order to satisfy the different preferences of the different channels in the group. Geographical diversity matters more than the size of the potential market.

Kanwal and Sukhmani (2011) examined a study of television viewership patterns among youngsters in Northern India. They observed that today television is considered to be a major source of entertainment and learning for many, especially the young. All television programs, especially the commercials, news, documentaries and cartoons, affect people of all ages in different ways. Youngsters constitute one of the groups in society who spend a lot of time watching television. In recent years, youngsters are even named as "active media users". The study was conducted to take note of various television-viewing habits among youngsters of Northern India and to identify the factors, which encourage television viewership among youngsters. The duo observed that Television has become one of the most important mass media tools especially in recent years and that its habits consist of patterns of behavior determined by the amount of time and importance individuals give to watching television broadcasts and recorded videos and DVDs.

This study was conducted in Northern region of India, a sample of minimum respondents were selected from the different states which included Punjab, Haryana, Himachal Pradesh, Jammu and Kashmir, and Jharkhand. An effort had been made to select the respondents evenly. The survey was carried out on 800 respondents. However, 47 Questionnaires were found to be incorrect, so a total of 50 questionnaires were deliberately rejected. Hence the study sample was reduced to 750 respondents. The data was collected personally (and via emails) in the months of October 2010 to April 2011. The respondents were delibrately selected to maintain equal distribution in age and gender specifications. There were 375 males and 375 females whose responses were selected for analysis. Also, effort has been made for equal distribution in age groups, 250 respondents being selected for analysis in each of the 3 categories of 16-20, 21-25 and 26-30 age groups. Most of the respondents were well educated, 68\% of the total respondents were either graduates and post graduates, with only around $27 \%$ being undergraduates. Factor Analytic approach was applied on 14 statements to find the reasons for television viewership. The study also highlighted the TV program preferences among youngsters.

The findings of the study reveal that most of the young indians watch television either most often and sometimes spend about 3-5 hours daily. It can be further concluded from the study that there was no significant difference in frequency of watching television between Males and Females, with almost equal mean average scores of around 2.67 as shown by the t-values. With increase in age and changes in education levels, there was no significant change in the pattern of television viewing, as shown by similar mean and f-ratio values. However, with increase in 
income the viewers tend to watch less television. The study also highlights the various reasons for Indian youth to watch television, mainly four factors emerged as most significant which includes, Generation of knowledge and learning, medium of relaxation and pass time, upliftment of hidden talents and stress management tool. It can be concluded that most of the young Indians view television as a learning tool and their favorite time pass activity. Some of the respondents view it as technique to polish their talents and others use television as a stress management tool to counter their stressful work life. It can be concluded from the study that males preferred "knowledge based programs" and females mostly prefer watching "movies". It could be seen that "music programs" are least preferred by males and females. All the age groups consistently preferred "reality shows" whereas "news coverage" was more preferred by higher age groups. Also, it was seen that under graduates prefer watching "cartoon shows" and as the education level increases the preference shifts to "reality shows" and "news coverage". Also, it can be concluded that with increase in income the preference shifts from "daily serials" to "news coverage".

Manit and Hitoshi (2013) analyzed factors affecting the adoption of Digital Terrestrial Television (DTTV) services in Thailand. The objective of their study was to examine and understand factors that contribute to consumer intention to adopt DTTV. The study tried to evaluate the benefits of consumers' adoption of DTTV services by analyzing consumers' valuations on DTTV's characteristics such as improved video quality, more available TV channels, and other enhanced services against how much they want to pay for a set-top box (STB) or a new digital TV (DTV). According to the duo, Digital television (DTV) has several advantages over analog TV. DTV enables television stations to provide dramatically clearer pictures and better sound quality. By transmitting the information used to make a TV picture and sound as "data bits" like a computer, television stations can also carry more information using digital broadcasting than is currently possible with analog broadcast technology. This means that digital broadcasters can provide more digital channels in the same space, deliver high-definition television service for consumers with high definition television sets, offer such basic data services as closed-captioning, electronic program guides and additional languages (spoken or subtitled), and allow other advanced services such as live broadcasting and interactivity functionality.

The duo employed a stated preference conjoint analysis method as a way to collect the data from viewers across Thailand. Using such data, consumers' utilities were estimated by applying a discrete choice model to determine important factors and measure their significance. The willingness to pay for each factor by consumers will be also calculated. From the 441 valid samples, $228(52 \%)$ respondents preferred adopting set-top box (STB) as a reception device for DTTV services and 213 (48\%) chose DTV. The distribution of age between STB adopters and DTV adopters in the survey is similar in which majority's ages are from 20 to 39 years old. Both adopter groups have percentage of female respondents more than male. For the income distribution, it can be seen that higher income respondents (more than 20,000 Baht) prefer adopting DTVs while lower income respondents (lower than 20,000 Baht) tend to adopt STBs. Lastly, the levels of educations between two groups are similar.

Also, from the results of the survey, it was discovered that the majority of respondents $(85 \%)$ still use CRT TVs at home. The questionnaire indicates that DTV adopter respondents are currently using flat screen TVs such as LCD and LED TVs more than STB adopter respondents. 
In general, the video quality in flat screen TV is better than in normal CRT TVs. This implies that DTV adopters value picture quality more than the counterparts. The respondents were also asked questions about the time spent on activities per day. The results indicate that STB adopters spend about 4 hours per day for watching TV, while the number for STB adopters is 5 hours. While STB adopters spend about 1.4 hours per day to surf the Internet, DTV adopters use more than 2 hours for the Internet daily. Moreover, the survey suggests that DTV adopters are those who at home use broadband Internet more at $40 \%$ compared to only $25 \%$ of STB adopters. In addition, results showed that DTV adopters spend about one hour to read newspaper while STB adopters only spend half of the time. These survey results suggest that DTV adopters are interested in retrieving information contents both online and offline more than those STB adopters.

In terms of awareness of DTTV services, about $18 \%$ of the STB adopters have heard about DTTV services, while approximately $31 \%$ of DTV adopters know about the term "DTTV". In addition, for those respondents who knows about DTTV services, DTV adopters understand about different features of DTTV services than STB adopters. This information implies that DTV adopter respondents have more knowledge about DTTV services than STB adopters do.

James, Daniel and Nnamdie (2017) studied influence of foreign television programmes on the westernization of Nigerian youths. The study examines the influence of television on the westernization of Nigerian youths. It is noteworthy that there is a growing worry over the decline of the cultural values of Nigerian youth. This ugly situation is sometimes tied to the influence of foreign television programmes. The foreign programmes do not only undermine the cultural values of Nigerian youths, but also influence the youths' behaviour as well as the prevalence of foreign attitudes and habits among them. The study is driven by cultivation theory which suggests that heavy television viewing "cultivates" perceptions of reality consistent with the view of the world presented in television programmes. Some youth in Nigeria, considerably perceive that what they view on foreign television programmes is a reality, and to them, there is need to cultivate the habits, attitudes, behaviour and values as demonstrated in television programmes.

The study adopted cultivation theory which is a social theory, otherwise known as cultivation analysis developed on the basis of examining the long term effects of television on audiences. The theory was developed by George Gerbner and Larry Gross of the University of Pennsylvania, the cultivation theory was derived from several large-scale projects as part of an overall research project. It was to identify and track the cultivated effects of television on viewers. They were concerned with the effects of television programming, particularly violent programming, on the attitudes and behaviour of the American public. The theory suggests that heavy television viewing "cultivates" perceptions of reality consistent with the view of the world presented in television programmes.

Findings showed that the amount of violence on television is on the rise. Perhaps, this is because the rate at which youth like to view violent acts on television now increases. Exposure to heavy doses of television violence increases aggressive behaviour, particularly in boys. Many studies link television or newspaper publicity of suicides to an increased suicide risk. He maintained that the following groups of children may be more vulnerable to violence on television: children from minority and immigrant groups; emotionally disturbed children; 
International Journal of Business and Management Review

Vol.8, No.2, pp.1-36, March 2020

Published by ECRTD-UK

Print ISSN: 2052-6393(Print), Online ISSN: 2052-6407(Online)

children with learning disabilities; children who are abused by their parents; and children whose families are in distress.

Domirani, Abbasali, Narges and Behnam (2014) examined an investigation of the Cultural Impacts of Globalization on the National Media (Television). Their study aimed to investigate the cultural impacts of globalization on television as the national medium from the perspective of media management and cultural management students from Science and Research Branch, Azad University of Tehran. Undoubtedly, the reflection of the cultural impacts of globalization on the national media would be outlined in the society as well as the nation's culture. Hence, due to the power of media over community in terms of audience and their culture, investigating the cultural impacts of globalization on television as a social medium could reflect the society's culture in the globalization era and as a result of globalization process. In view of globalization progress and procession of the world's entire media towards this direction, it would be necessary that the national media as well follows this trend in order to lay out the required information for the decision-makers and avoid future problems associated with the national media which might occur in accordance to the fast pace of changes.

The study was conducted by survey and a designed questionnaire was constructed for data collection purposes. The study population comprised all students of cultural affairs management, cultural affairs planning, cultural affairs management and planning, cultural management and planning, decision-making and policy-making and media management from Science and Research Branch, Islamic Azad University of Tehran; of whom 160 candidates were selected as sample population to complete the designed questionnaire according to the sample size table by Krejcie and Morgan. Descriptive analysis of data was done using frequency distribution tables and percentile ranks whereas inferential analysis was carried out through one-sample median test, Pearson correlation and Chi-Square test for examining the hypothesis while taking the level of variable evaluation into the account.

When respondents were asked how they would rank the impact of the global skilled intellectual and professional personnel's knowledge on reinforcement of the national media's educational programmes, $88 \%$ considered this impact "average" while the remaining $9 \%$ considered it "low" and "very low". Meanwhile, majority of the respondents gave the impact of global education on reinforcement of the national media's educational programmes, a rating of "high". Similarly, the impact of uniformity in education and global standards on reinforcement of the national media's educational programmes was regarded as "high" by $87 \%$ of the respondents. $89 \%$ of the respondents reported that they believed the spread of the English language could exert "high" impact on reinforcement of the national media's educational programmes. With respect to the impact of virtual education in the global village on impact on reinforcement of the national media's educational programmes, solely a mere 5.6\% considered it "high". $15.6 \%$ believed it to have an "average" impact while majority of the respondents (79\%) considered the impact to be "low". On the contrary, $87.5 \%$ of the respondents stated that the impact of the widespread utilisation of the new technologies on reinforcement of the national media's educational programmes was either "high" or "very high". Furthermore according to the vast majority of the respondents (89\%), the impact of an increase in the number of the academic degrees and intellectual rankings conferred by the overseas universities and educational institutes on reinforcement of the national media's educational programmes was considered "high". From the viewpoint of $25.6 \%$ of the respondents, generation of self-awareness skills 
on the basis of ultra-nationalistic facts had "high" impact on the national media's educational programmes, while $56 \%$ considered it "average" and $18 \%$ considered it. The survey report also demonstrated that according to the perspective of $90.6 \%$ of the respondents, growing tendencies toward fashion in terms of clothing and outfit had either "high" and "very high" impact on the national media's educational programmes. Virtually all of the respondents $(99 \%)$ agreed on "very high" and "high" impact of growing interest toward possession of expensive and luxurious cars on the national media's educational programmes. Similarly, a vast majority of respondents reported "high" and "very high" impact of the increasing trend toward consumption of fast food instead of the traditional foods on the national media's educational programmes.

Jense and Oster (2008) investigated the power of television: cable television and women's status in India. This study explored the effect of the introduction of cable television in rural areas of India on a particular set of values and behaviors, namely attitudes towards and discrimination against women. Although issues of gender equality are important throughout the world, they are particularly salient in India. Beyond providing entertainment, television vastly increases both the availability of information about the outside world and exposure to other ways of life. This is especially true for remote, rural villages, where several ethnographic and anthropological studies have suggested that television is the primary channel through which households get information about life outside their village (Mankekar 1993, 1998; Fernandes 2000; Johnson 2001; Scrase 2002). Most popular cable programming features urban settings where lifestyles differ in prominent and salient ways from those in rural areas. For example, many characters on popular soap operas have more education, marry later and have smaller families, all things rarely found in rural areas; and many female characters work outside the home, sometimes as professionals, running businesses or in other positions of authority. Anthropological accounts suggest that the growth of television in rural areas has had large effects on a wide range of day-to-day lifestyle behaviors, including latrine building and fan usage.

The primary dataset is the Survey of Aging in Rural India (SARI), a panel survey of 2,700 households, each containing a person aged 50 or older, conducted in 2001, 2002 and 2003 in four states (Bihar, Goa, Haryana and Tamil Nadu), and the capital, Delhi. The sample was selected in two stages: in the first stage, 180 villages were selected at random from district lists (40 villages in Bihar, Haryana and Tamil Nadu, 35 in Delhi and 25 in Goa), and in the second stage, 15 households were chosen within each village through random sampling based on registration lists. Other than Delhi, the survey was confined to rural areas. Attrition over the panel was low, with just 108 (4 percent) of the original households dropping out by the third round. 
Findings show that the percent of women who report they watch television at least once a week (unfortunately, the survey did not gather data on the amount of time spent watching). The graph shows viewership for each year for women in four groups of villages: those that already have cable as of 2001, those that add cable in 2002, those that add cable in 2003, and those that never get cable during our survey. Overall, there is relatively little change in watching over time in either areas that never have cable or those that always have it. However, in villages that get cable in 2002, the share of respondents who report watching television at least once a week jumps from 40 to 80 percent between 2001 and 2002; in villages that get cable in 2003, this share is constant between 2001 and 2002, then increases sharply from 50 to 90 percent between 2002 and 2003. This graph suggests a strong connection between cable availability and television viewership, with a near doubling in both cases.

In this paper, it was found that the introduction of cable television improves the status of women: women report lower acceptability of spousal abuse, lower son preference, more autonomy and lower fertility. In addition, cable is associated with increases in school enrollment, perhaps itself an indicator of increased women's status and decision-making authority within the household. Thus, programs to provide televisions, such as the large program currently underway in Tamil Nadu, may in fact have significant implications for important development priorities.

Zixuan (2011) examined the impact of American television on Chinese college students. The study examined the viewing of American television among Chinese college students and the relationship between American television exposure and its impact in terms of value, knowledge, belief, attitude and behavior. This study proposes to examine the increasing popularity of American Television in China as well as its impact, that is, to take a closer look at American TV viewing in China and its influence on Chinese audience.

A cross-sectional survey was conducted with a sample of Chinese college students. Participants were asked to finish a Chinese-language online survey which was original designed in English and translated into Chinese using back translation. The questionnaire contained four major parts: (1) demographic information (2) media exposure (3) viewing habit (4) impact. The questionnaire was voluntary, anonymous and self-administered, and takes about 15 minutes to complete. Participants in the study were recruited using snowball sampling method (Network Sampling) technique. College students were chosen as the sample because they represent a great portion of Chinese culture as well as the fact that they have the technological means to get access to American Television. A total of 279 students were interviewed and data were analyzed using SPSS. Factor analysis was used to explore the underlying dimensions of 40 items CVS and the 64 cultivation items, and new variables were created after factors were identified. Demographic information and the viewing habit data were analyzed initially using descriptive statistics in order to describe the sample and their viewing pattern. Inferential statistical analyses such as T-test ANOVA, Correlation and Regression were also conducted. 
The results indicated that female students and students from urban areas are more likely to watch American TV shows. Regarding the exposure questions such as amount of time spent, viewing channel, preference in different genres, gratification sought and obtained and so forth, interesting results were found as discussed in the result section. The results confirmed some of the speculations: a large amount of college students (86.3\%) watch American TV shows and many of them can be categorized as heavy/regular/long-term/high viewers; Chinese viewers least watch American TV shows through TV broadcasting, instead, the Internet has become the most popular platform for American TV; In terms of the forms of the programs, most viewers prefer subtitles to dubbing, which should have drawn more attention from the policy makers in the general office of Broadcasting and Television. Moreover, Chinese viewer's preference in genre is different from American viewers.

According to Nielsen ratings, reality TV shows such as American Idol are extremely popular among American viewers, while comedy is most popular among Chinese viewers. What also should be noticed is that most college student viewers watch American TV for English learning and relaxation, which could be a possible explanation for the different preference in genre. Finally, plot or story line is definitely the most important factor that affects the Chinese viewer's choice in American TV shows as well as the most appealing characteristic of American TV. 


\section{Operationalized Model for the Study}

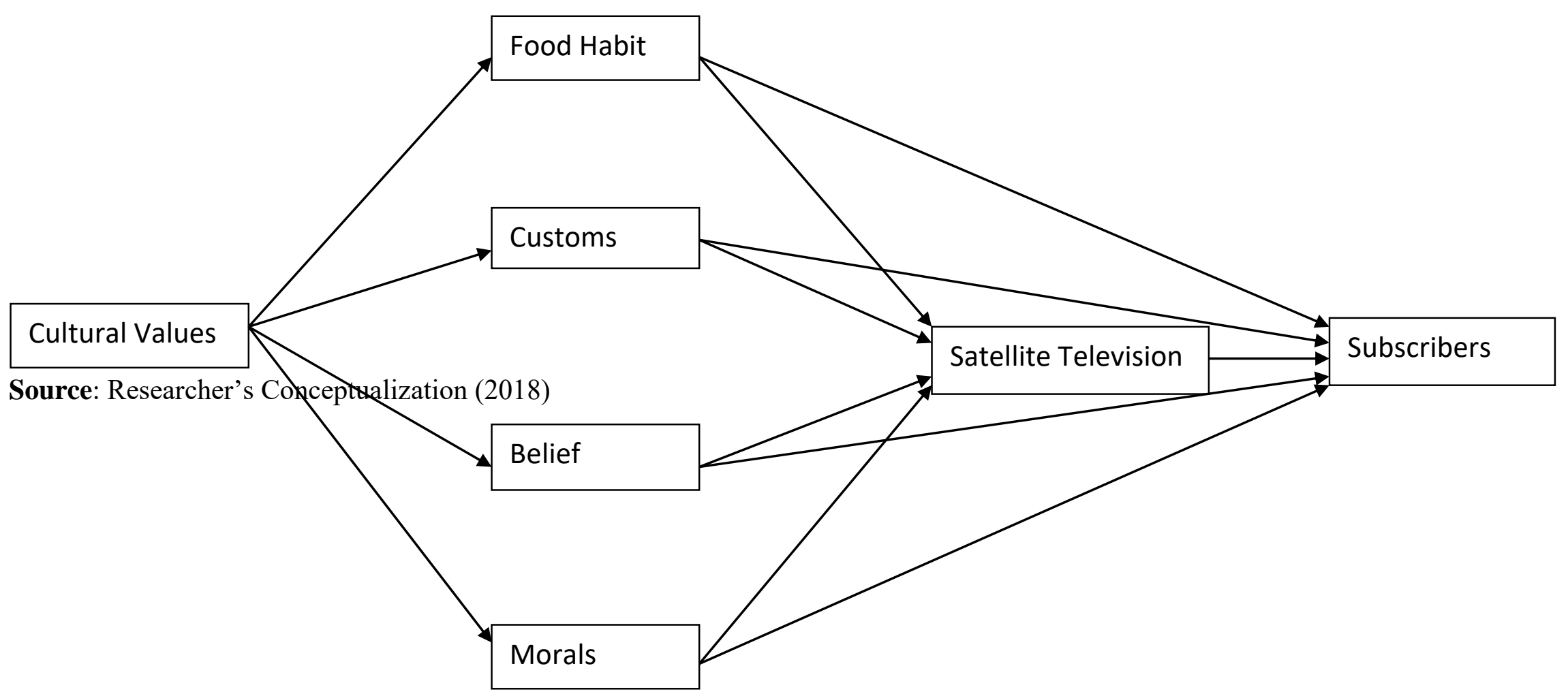




\section{MATERIALS AND METHODS}

This study adopted a descriptive survey research design because it is well-matched to (1) describe characteristics of certain groups (2) determine the proportion of youths who behave in a certain way upon exposure to Western television content (3) make specific predictions and (4) determine relationships between variables. In a nutshell, descriptive research provides an accurate portrayal or account of the behaviour, opinions, beliefs, and knowledge of a particular individual or group.The study was conducted in Ekiti, Ondo and Osun States in Nigeria.The study population comprised of subscribers of major Satellite Television in Nigeria especially in the South West. They include subscribers of Startimes, GoTV, DSTV and MYTV. The Table 1 below represents the total number of the subscribers which represents the population for the study.

Table 1: Distribution of Satellite Television Subscribers in South-West Nigeria.

\begin{tabular}{llllll}
\hline States & Startimes & GoTV & DSTV & MYTV & Total \\
\hline Ogun & 90 & 67 & 126 & 42 & 325 \\
Ondo & 95 & 80 & 105 & 48 & 328 \\
Ekiti & 65 & 75 & 76 & 34 & 250 \\
Osun & 53 & 47 & 63 & 29 & 192 \\
Oyo & 90 & 67 & 126 & 42 & 325 \\
Lagos & 102 & 79 & 142 & 69 & 392 \\
Total & 405 & 348 & 512 & 222 & 1487 \\
\hline
\end{tabular}

Source: Field Survey (2018).

The sample size for this study consists of 180 respondents. Firstly, the sample size was selected by randomly selecting one state out of the six states in South-Western Nigeria. Furthermore, One Local Government Area was randomly picked from the selected state. The selected Local Government Area was later divided into ten (10) wards. Secondly, each ward was divided into nine $\{9)$ streets. By implication, there are total of ninety (90) streets within the wards. Finally, two (2) houses were randomly selected (through balloting) from each street to select a subscriber who took part in the study. For the purpose of testing hypotheses or answering questions the researcher decided to adopt a closed-ended questionnaire titled "Preference of Satellite Television on the Cultural Value Orientation of people in the South-Western states of Nigeria (PSTCVOP)". In the closed-ended questions, participants were required to respond to options which were determined by the researcher. The questionnaire contained two sections. The first section dealt with respondents' demographic data such as age, level of education and gender. The second section aimed at determining the knowledge and views of participants on media imperialism through Satellites Television programmes and its effects on indigenous culture. The rating techniques were based on a- 4 point Likert type scale ranging from strongly agree (SA) with 4 points to Strongly Disagree (SD) with 1 point as shown below:

$\begin{array}{ll}\text { Strongly Agree (SA) } & -4 \text { Points } \\ \text { Agree (A) } & -3 \text { Points } \\ \text { Disagree (D) } & -2 \text { Points } \\ \text { Strongly Disagree (SD) } & -1 \text { Point }\end{array}$


In dealing with the problem at hand it is necessary to collect data that are adequate and appropriate. The researcher opted to collect primary data using the survey method which involved the use structured questionnaire as against experimental method. Although the experimental method would allow the researcher to examine the truth contained in his hypothesis, the survey method provides the best means of collecting the views of respondents regarding their preference for Satellites television and its impacts on their perceptions, ideologies and behaviours. It is the most commonly used data collection method in the behavioural sciences, and; it involves drawing up a set of questions on various subjects or aspects of a subject to elicit the views of a group, people or study population about an event, activity or phenomenon.

The instrument, Questionnaire on preference of Satellite television on the cultural value orientation of people in the South-Western states of Nigeria" (PSTCVOP) used for the study was subjected to face and content validity procedures. For face validity, the experts determined the face level of appropriateness of the instruments in measuring what they purport to measure and ensure that the instruments contained the appropriate items that could actually elicit the intended responses. Experts' judgments were also used in determining the content validity. The experts took time to check the extent to which the items of the instrument are representative of the contents and behaviour specified by the theoretical concept being measured. Also, the research questions, hypotheses and the questionnaires were made available to my supervisor who effected some corrections and later confirmed that the instruments were valid.

A great deal of attention is applied to reliability and validity in all research methods. (Morse et al., 2002)" Likewise, (Merriam, 1998) contends that educational research studies can only effect educational theory or practice if it is rigorous and presents results that are acceptable to other educators and researchers. To accomplish this task, studies must be of high quality and results must be trustworthy and dependable. The reliability of the questionnaire was established through the test- retest method. This involved the administration of the questionnaire to 20 respondents in one local government which will not be included in the study. The questionnaire was administered twice within an interval of two weeks. Two sets of responses were correlated using Pearson Moment Correlation. Reliability Coefficient 0.81 was obtained. This was considered high enough to make the instrument reliable. The data collected were analyzed using descriptive and inferential statistics. Descriptive statistics such as simple percentages, mean and standard deviation were used to answer the research questions while inferential statistics involving Regression was used to test the hypothesis at 0.05 level of significance.

\section{ANALYSIS AND RESULTS}

A total of one hundred and eighty (180) questionnaires were administered and all were retrieved. Below shows the presentation according to the research question raised from the study.

Question 1 What is the relationship that exist between Satellites Television Programmes and the food habits of subscribers in South-West Nigeria? 
Table 2: Relationship that exist between Satellites Television Programmes and the food habits of subscribers in South-West Nigeria.

\begin{tabular}{|c|c|c|c|c|c|c|}
\hline$\overline{\mathbf{S} / \mathbf{N}}$ & ITEMS & $\begin{array}{l}\text { SA } \\
(\%)\end{array}$ & $\begin{array}{l}\text { A } \\
(\%)\end{array}$ & $\begin{array}{l}D \\
(\%)\end{array}$ & $\begin{array}{l}\text { SD } \\
(\%)\end{array}$ & Mean \\
\hline$A_{1}$ & $\begin{array}{l}\text { Nigerians appreciate western diet more than } \\
\text { indigenous type due to preference for } \\
\text { Satellite Television }\end{array}$ & $\begin{array}{l}56 \\
(31.1)\end{array}$ & $\begin{array}{l}47 \\
(26.1)\end{array}$ & $\begin{array}{l}35 \\
(19.4)\end{array}$ & $\begin{array}{l}42 \\
(23.3\end{array}$ & 2.65 \\
\hline $\mathrm{A}_{2}$ & $\begin{array}{l}\text { Preference for foreign diets cuts across all } \\
\text { and sundry in Nigeria. }\end{array}$ & $\begin{array}{l}116 \\
(64.4)\end{array}$ & $\begin{array}{l}27 \\
(15.0)\end{array}$ & $\begin{array}{l}26 \\
(14.4)\end{array}$ & $\begin{array}{l}11 \\
(6.1)\end{array}$ & 3.38 \\
\hline $\mathrm{A}_{3}$ & $\begin{array}{l}\text { Nigerian government promotes foreign diets } \\
\text { through commercial patronage during } \\
\text { various functions }\end{array}$ & $\begin{array}{l}62 \\
(34.4)\end{array}$ & $\begin{array}{l}85 \\
(47.2)\end{array}$ & $\begin{array}{l}37 \\
(20.6)\end{array}$ & $\begin{array}{l}4 \\
(2.2)\end{array}$ & 3.23 \\
\hline $\mathrm{A}_{4}$ & $\begin{array}{l}\text { I derived much pleasures in foreign diets than } \\
\text { local meal }\end{array}$ & $\begin{array}{l}72 \\
(40.4)\end{array}$ & $\begin{array}{l}38 \\
(21.1)\end{array}$ & $\begin{array}{l}16 \\
(8.9)\end{array}$ & $\begin{array}{l}54 \\
(30.0)\end{array}$ & 2.71 \\
\hline
\end{tabular}

Table 1 presents the relationship that exist between Satellite Television programs and food habits by the people in South-West, Nigerian. The result shows that 56 respondents representing $31.1 \%$ of the total sample strongly agreed that Nigerians appreciate foreign meals as of preference for Satellite Television. 47(26.1\%) agreed, 35(19.4\%) disagreed while 42(23.3\%) strongly disagreed. On whether preference for foreign diets cuts across all and sundry in Nigeria, $116(64.4 \%)$ respondents strongly agreed, 27(15\%) agreed, 26(14.4\%) disagreed and 11(6.1\%) strongly disagreed. $62(34.4 \%)$ respondents strongly agreed that Nigerian government promotes the consumption of western diet through commercial patronage, 85(47.2\%) agreed, 37(20.6\%) disagreed and $4(2.2 \%)$ strongly disagreed. On whether the respondents derived much pleasure in western diet based on preference for Satellite Television, 72(40./4\%) respondents strongly agreed, 38(21.1\%) agreed, 16(8.9\%) disagreed and 54(30\%) strongly disagreed.

Using a cutoff mean score of 2.50 for the rating scale, all the items had mean scores above the cutoff point which has been indicated in the above table for the purpose of evaluation. This implies that to which Satellites Television Programmes has a negative relationship, that is, it has negative effect on the food habits of subscribers in South-West Nigeria is high. 
International Journal of Business and Management Review

Vol.8, No.2, pp.1-36, March 2020

Published by ECRTD-UK

Print ISSN: 2052-6393(Print), Online ISSN: 2052-6407(Online)

Question 2 What is the relationship between Satellite Television preferences and customs of people in South-West Nigeria?

Table 3: Relationship between Satellite Television preferences and customs of people in South-West Nigeria.

\begin{tabular}{|c|c|c|c|c|c|c|}
\hline$\overline{\mathbf{S} / \mathbf{N}}$ & Items & $\begin{array}{l}\text { SA } \\
(\%)\end{array}$ & $\begin{array}{l}A \\
(\%)\end{array}$ & $\begin{array}{l}\text { D } \\
(\%)\end{array}$ & $\begin{array}{l}\text { SD } \\
(\%)\end{array}$ & Mean \\
\hline$\overline{\mathrm{B}_{1}}$ & $\begin{array}{l}\text { Preference for Satellites television } \\
\text { programme has led to massive conflict with } \\
\text { the indigenous cultural values of the } \\
\text { Nigerian people }\end{array}$ & $\begin{array}{l}46 \\
(25.6)\end{array}$ & $\begin{array}{l}69 \\
(38.3)\end{array}$ & $\begin{array}{l}27 \\
(15.0)\end{array}$ & $\begin{array}{l}38 \\
(21.1)\end{array}$ & 2.68 \\
\hline $\mathrm{B}_{2}$ & $\begin{array}{l}\text { Preference for Satellites Television } \\
\text { Programmes has affected youth behavioural } \\
\text { approaches. }\end{array}$ & $\begin{array}{l}59 \\
(32.8)\end{array}$ & $\begin{array}{l}61 \\
(33.9)\end{array}$ & $\begin{array}{l}41 \\
(22.8)\end{array}$ & $\begin{array}{l}19 \\
(10.6)\end{array}$ & 2.89 \\
\hline$B_{3}$ & $\begin{array}{l}\text { Preference for Satellites television had } \\
\text { impacted negatively on Nigerian sexual } \\
\text { orientation. }\end{array}$ & $\begin{array}{l}71 \\
(39.4)\end{array}$ & $\begin{array}{l}33 \\
(18.3)\end{array}$ & $\begin{array}{l}29 \\
(16.1)\end{array}$ & $\begin{array}{l}47 \\
(26.1)\end{array}$ & 2.71 \\
\hline $\mathrm{B}_{4}$ & $\begin{array}{l}\text { Foreign television programmes has } \\
\text { adjusted the mode of greetings of an } \\
\text { average Nigerian. }\end{array}$ & $\begin{array}{l}48 \\
(26.7)\end{array}$ & $\begin{array}{l}71 \\
(39.4)\end{array}$ & $\begin{array}{l}29 \\
(16.1)\end{array}$ & $\begin{array}{l}32 \\
(17.8)\end{array}$ & 2.75 \\
\hline
\end{tabular}

Table 2 presents the effects of Satellite Television preferences on cultural values of people in South-West Nigerian. The result shows that 46(25.6\%) of the total sample strongly agreed that preference for Satellites television programme has led to massive conflict with the indigenous cultural values of the Nigerian people, 69(38.3\%) agreed, 27(15\%) disagreed and 38(21.1\%) strongly disagreed. On whether preference for Satellites Television Programmes has affected youth behavioural approaches, 59(32.8\%) strongly agreed, 61(33.9\%) agreed, 41(22.8\%) disagreed and 19(10.6\%) strongly disagreed. 71(39.4\%) respondents strongly agreed that preference for Satellites television had impacted negatively on Nigerian sexual orientation, $33(18.3 \%)$ agreed, $29(16.1 \%)$ disagreed and 47(26.1\%) strongly disagreed. On whether foreign television programmes has adjusted the mode of greetings of an average Nigerian, 48(26.7\%) respondents strongly agreed, 71(39.4\%) agreed, 29(16.1\%) disagreed and 32(17.8\%) strongly disagreed.

With a cutoff mean score of 2.50 for the rating scale, all the items had mean scores above the cutoff point indicated in the above table for the purpose of evaluation. This implies that massive conflict with the indigenous cultural values of the Nigerian people, negative behavioural approaches of the youths, negative sexual orientation and adjustment in mode of greetings of the citizens are prominent effects of Satellite Television preferences on customs of people in SouthWest Nigerian. 
Print ISSN: 2052-6393(Print), Online ISSN: 2052-6407(Online)

Question 3. What is the relationship that exists between preference for Satellite Television programmes and viewer's beliefs?

Table 4: Relationship that exist between preference for Satellite Television programmes and viewer's beliefs.

\begin{tabular}{|c|c|c|c|c|c|c|}
\hline$\overline{\mathbf{S} / \mathbf{N}}$ & ITEMS & $\begin{array}{l}\text { SA } \\
(\%)\end{array}$ & $\begin{array}{l}\mathrm{A} \\
(\%)\end{array}$ & $\begin{array}{l}\mathrm{D} \\
(\%)\end{array}$ & $\begin{array}{l}\text { SD } \\
(\%)\end{array}$ & Mean \\
\hline $\mathrm{C}_{1}$ & $\begin{array}{l}\text { Nigerians no longer give due respect to leadership as a } \\
\text { result of preference for Satellite television. }\end{array}$ & $\begin{array}{l}68 \\
(37.8)\end{array}$ & $\begin{array}{l}91 \\
(50.6)\end{array}$ & $\begin{array}{l}10 \\
(5.6)\end{array}$ & $\begin{array}{l}11 \\
(6.1)\end{array}$ & 3.20 \\
\hline $\mathrm{C}_{2}$ & $\begin{array}{l}\text { Wide coverage of Satellite television has reduced the fear } \\
\text { Nigerians has in ancestral gods. }\end{array}$ & $\begin{array}{l}100 \\
(55.6)\end{array}$ & $\begin{array}{l}37 \\
(20.6)\end{array}$ & $\begin{array}{l}21 \\
(11.7)\end{array}$ & $\begin{array}{l}22 \\
(12.2)\end{array}$ & 3.19 \\
\hline $\mathrm{C}_{3}$ & $\begin{array}{l}\text { Exposure to varieties of information has made children to } \\
\text { lose interest in old tales. }\end{array}$ & $\begin{array}{l}47 \\
(26.1)\end{array}$ & $\begin{array}{l}86 \\
(47.8)\end{array}$ & $\begin{array}{l}43 \\
(23.9)\end{array}$ & $\begin{array}{l}4 \\
(2.2)\end{array}$ & 2.98 \\
\hline $\mathrm{C}_{4}$ & $\begin{array}{l}\text { Globalization Played a vital role in changing the way } \\
\text { marriages are conducted. }\end{array}$ & $\begin{array}{l}26 \\
(14.4)\end{array}$ & $\begin{array}{l}99 \\
(55.0)\end{array}$ & $\begin{array}{l}16 \\
(8.9)\end{array}$ & $\begin{array}{l}39 \\
(21.7)\end{array}$ & 2.62 \\
\hline
\end{tabular}

Table 3 presents the relationship that exists between preferences of Satellite Television programs and viewers' beliefs. The result reveals that $68(37.8 \%)$ of the total sample strongly agreed that Nigerians no longer give due respect to leadership as a result of preference for Satellite television, 91(50.6\%) strongly agreed, 10(5.6\%) disagreed and 11(6.1\%) strongly disagreed. 100(55.6\%) of the respondents strongly agreed that wide coverage of Satellite television has reduced the fear Nigerians has in ancentral gods. 37(20.6\%) agreed, 21(11.7\%) disagreed and 22(12.2\%) strongly disagreed. Regarding exposure to varieties of information making the children to lose interest in old tales, 47(26.1\%) respondents strongly agreed, 86(47.8\%) agreed, 43(23.9\%) disagreed and $4(2.2 \%)$ strongly disagreed. $26(14.4 \%)$ respondents strongly agreed that globalization played a vital role in changing the way marriages are conducted, 99(55\%) agreed, 16(8.9\%) disagreed and $39(21.7 \%)$ strongly disagreed.

Using a cutoff mean score of 2.50 for the rating scale, all the items had mean scores above the cutoff mean indicated in the above table for the purpose of evaluation. This implies that lack of due respect for elders, reduced fear for the gods, loss of interest in old tales and changes in the method in which marriages are conducted are directly related to preference for Satellite Television programs by Nigerian subscribers.

\section{Question 4}

What is the relationship between Satellite Television and morals of subscribers in South-West Nigeria? 
Print ISSN: 2052-6393(Print), Online ISSN: 2052-6407(Online)

Table 5: Relationship between Satellite Television and morals of subscribers in South-West Nigeria

\begin{tabular}{|c|c|c|c|c|c|c|}
\hline $\mathbf{S} / \mathbf{N}$ & ITEMS & $\begin{array}{l}\text { SA } \\
(\%)\end{array}$ & $\begin{array}{l}\text { A } \\
(\%)\end{array}$ & $\begin{array}{l}\text { D } \\
(\%)\end{array}$ & $\begin{array}{l}\text { SD } \\
(\%)\end{array}$ & Mean \\
\hline $\mathrm{D}_{1}$ & $\begin{array}{l}\text { Foreign media should be held responsible if } \\
\text { indecent dressing persist in Nigeria. }\end{array}$ & $\begin{array}{l}41 \\
(22.8)\end{array}$ & $\begin{array}{l}68 \\
(37.8)\end{array}$ & $\begin{array}{l}34 \\
(18.8)\end{array}$ & $\begin{array}{l}37 \\
(20.6)\end{array}$ & 2.63 \\
\hline $\mathrm{D}_{2}$ & $\begin{array}{l}\text { The emergence of Satellite television has } \\
\text { drastically affected language of an average } \\
\text { Nigerian viewers. }\end{array}$ & $\begin{array}{l}81 \\
(45.0)\end{array}$ & $\begin{array}{l}27 \\
(15.0)\end{array}$ & $\begin{array}{l}31 \\
(17.2)\end{array}$ & $\begin{array}{l}41 \\
(22.8)\end{array}$ & 2.82 \\
\hline $\mathrm{D}_{3}$ & $\begin{array}{l}\text { Cultism on Nigeria campuses is traceable to } \\
\text { preference for Satellite television. }\end{array}$ & $\begin{array}{l}29 \\
(16.1)\end{array}$ & $\begin{array}{l}79 \\
(43.9)\end{array}$ & $\begin{array}{l}51 \\
(28.3)\end{array}$ & $\begin{array}{l}21 \\
(11.7)\end{array}$ & 2.64 \\
\hline $\mathrm{D}_{4}$ & $\begin{array}{l}\text { Satellite television has led to unprecedented } \\
\text { rise in criminal activities among the Nigerian } \\
\text { youths. }\end{array}$ & $\begin{array}{l}64 \\
(35.6)\end{array}$ & $\begin{array}{l}102 \\
(56.7)\end{array}$ & $\begin{array}{l}27 \\
(15.0)\end{array}$ & $\begin{array}{l}13 \\
(7.2)\end{array}$ & 3.49 \\
\hline
\end{tabular}

Table 4 presents the effects of Satellite Television on morals of subscribers in South-West Nigeria result shows that 41 respondents representing $22.8 \%$ of the total sample strongly agreed that foreign media should be held responsible if indecent dressing persist in Nigeria, 68(37.8\%) agreed, 34(18.8\%) disagreed and 37(20.6\%) strongly disagreed. On whether the emergence of Satellite television has drastically affected language of an average Nigerian viewers, $81(45 \%)$ respondents strongly agreed, 27(15\%) agreed, 31(17.2\%) disagreed and 41(22.8\%) strongly disagreed. 29(16.1\%) respondents strongly agreed that cultism on Nigeria campuses is traceable to preference for Satellite television, 79(43.9\%) agreed, 51(28.3\%) disagreed and 21(11.7\%) strongly disagreed. On whether Satellite television has led to unprecedented rise in criminal activities among the Nigerian youths, 64(35.6\%) respondents strongly agreed, 102(56.7\%) agreed, 27(15\%) disagreed and 13(7.2\%) strongly disagreed.

Using a cutoff mean of 2.50 for the rating scale, all the items had mean scores above the cutoff point indicated in the above table for the purpose of evaluation. This implies that persistent indecent dressing, use of strange languages, unending cultism on our campuses and unprecedented rise in criminal activities among the Nigerian youths among others are some of the negative relationship of Satellite Television has with morals of subscribers in South-West Nigeria.

\section{Test of Hypotheses}

The hypotheses earlier stated, were formulated to direct the focus of this study was tested using regression analysis. 
International Journal of Business and Management Review

Vol.8, No.2, pp.1-36, March 2020

Published by ECRTD-UK

Print ISSN: 2052-6393(Print), Online ISSN: 2052-6407(Online)

Table 6: Regression analysis showing the contribution of Satellite television preference to cultural value orientation among people in South-Western states, Nigeria

$\begin{array}{cc}\begin{array}{c}\text { Unstandardized } \\ \text { Coefficients }\end{array} & \begin{array}{c}\text { Standardized } \\ \text { Coefficients }\end{array}\end{array}$

Std.

\begin{tabular}{|c|c|c|c|c|c|}
\hline Model & B & Error & Beta & $\mathbf{T}$ & Sig. \\
\hline (Constant) & 4.804 & 4.768 & & 1.008 & 0.315 \\
\hline Satellite Television preferences & 0.911 & 0.081 & 0.644 & 11.229 & 0.000 \\
\hline \multicolumn{6}{|c|}{ Multiple $\mathrm{R}=0.644$, Multiple $\mathrm{R}^{2}=0.415$, Adjusted $\mathrm{R}^{2}=0.411$, } \\
\hline
\end{tabular}

Table 5 reveals that there is significant contribution of Satellite Television preference to cultural value orientation among people in the South-Western states of Nigeria $\left(\mathrm{F}_{1,178}=126.092 ; \mathrm{p}<0.05\right)$. Therefore, the null hypothesis $\left(\mathrm{H}_{0}\right)$ is rejected while the alternate hypothesis $\left(\mathrm{H}_{\mathrm{o}}\right)$ is accepted. This implies that there is a positive and significant effect of cultural value orientation on Satellite television preference among people in the South-Western states of Nigeria. The relationship between cultural value orientation and Satellite television preference is high, positive and statistically significant at 0.05 level $(r=0.644, p<0.05)$. About $41.5 \%\left(R^{2}=0.415\right)$ of the observed variance in cultural value orientation among people in the South-Western states of Nigeria is explained by Satellite Television preferences. The remaining 58.5\% unexplained variance is largely due to other factors outside the regression model which are otherwise included in the stochastic error term.

\section{DISCUSSION}

The study x-rayed the cultural value orientation and Satellite television preference in the SouthWestern states of Nigeria. It was found that preference for Satellite Television programs has changed food habits of the people in South-West. In the Cultivation theory developed by Gerbner (1977), the theory proposes that repetitive or persistent consumption of certain media content leads to change of attitude, values and adoption. The theory, according to its proponent suggests that mass media, especially Satellite television, is responsible for molding viewers' perception of social reality.

The study revealed that massive conflict with the indigenous cultural values of the Nigerian people, negative behavioural approaches of the youths, negative sexual orientation and adjustment in the method of greetings of the citizens were prominent effects of Satellite Television preferences on cultural values of people in South-West Nigerian. The finding agrees with the study of Ward (2002) cited in Onyiengo (2014) that parents, educators, law enforcing officers and the clergymen have shown a great concern about the effects of western television programs on the environment, children and adults. The effect on reading, leisure time activities, and moral behavior has been alarming. Some of the studies conducted on television have concluded that it is a good influence; other said it was damaging.

The result showed that there was an inverse relationship existing between preference for Satellite Television and beliefs in the south western Nigeria. Nigerians, especially the youths, no longer give due respect to leadership, have reduced the fear in ancestral gods, have lost interest in old 
tales, have also changed the way marriages are conducted. All these are as a result of preference for Satellite Television. This finding has lent credence to the submission Patricia (2013) who argues that the culture of the African man is seen as his pride, thus, any danger that portends toward it is looked upon as a slap and derogation on the African's man pride. It is in this vein that Patricia (2013) posited that 'the character of the mass media is such that it is expected to bring about positive influence in the lives of its audience through contents that lend credence among other things to the preservation of the culture and intrinsic values of the society.

Another finding revealed that extinction of decent dresses, increased corrupt languages, persistent cultism on campuses and unprecedented rise in crime rate are negative influence of Satellite Television on morals of subscribers in the south western Nigeria. The finding agrees with the submission of Okonkwo (2008) who posited that Nigeria is now experiencing cultural inversion; foreign culture has eroded the cultural heritage of the people. The dilution of original culture is evident in youth dressing patterns, spoken words and other social adaptations. Many Nigerians have obvious preference to western style of dressing than indigenous dressing due to over indulgence in consuming western media content. Youths prefer to wear western dresses, speak with foreign accents, play foreign music and watch their movies so much so that they perceive themselves to be westerners.

Findings further showed that there was significant contribution of Satellite television preference to cultural value orientation among people in the South-Western states of Nigeria. The finding is favourably supported by Baran (2010) who argued that though globalized television content effect is undisputable, the internal government regulation over infiltration of foreign media and its content has helped to keep erosion of indigenous cultures in check.

\section{CONCLUSIONS}

This study has revealed that since most viewers in the south western Nigeria had strong preference towards watching Western entertainment television programmes, this responsible for continuous downward tune in the food habits, customs beliefs and morals of an average viewer. It is obvious therefore, that the main reason for exposure to the foreign cultural values is as a result of concentration on Satellite Television.

\section{Recommendations}

From this study, it was observed that Western entertainment television programmes largely influenced the mode of dressing, food habits and sexual orientation of Nigerian youths. The following recommendations are hereby put forward:

i. That television operators and producers need to revamp the culture of creative and original programming on Nigerian television stations as it is obvious if the programmes are interesting, youths will watch and ultimately learn from them.

ii. Programme producers of entertainment television stations should widen their area of coverage so as to make it interesting to the view and thereby promote the indigenous culture.

iii. It is also recommended that Nigerian government should create an enabling environment or local stations to run 24 hours programming with varieties of event that could successfully compete with Satellite Television programmes. 
International Journal of Business and Management Review

Vol.8, No.2, pp.1-36, March 2020

Published by ECRTD-UK

Print ISSN: 2052-6393(Print), Online ISSN: 2052-6407(Online)

iv. Nigerian cultural values should be embedded right from the infant stage to adulthood so as to discourage the influx of foreign culture that has pervaded our system

\section{Reference}

Ahmad. F., Latiffah. P., Samsudin. R. \& Mohd, H.A. (2012)."Representation of sexuality on television: Values and attitudes of young Malaysian". Asian Social Science, 8(7). 77-84.

Akintayo, J. B. \& Adebola, A. (2015). Western Entertainment Television Programmes: A Catalyst for Behaviourial Tendencies among Students of Babcock and Covenant Universities. New Media and Mass Communication, 42:56-68.

Anaeto, S. G, Onabajo, O. S. \& Osifeso, J. B. (2008). Models and Theories of Communication. African Renaissance Books Incorporated.

Apuke, O. D., \& Dogari, K. A. (2017). Western Television Programmes and Its Influence on the Cultural Values of Students in Taraba State University, Jalingo, Nigeria. Canadian Social Science, 13(1):1-32.

Bandura, A. (1997). Social foundations of thought and action: A social cognitive theory. Englewood, Cliffs, NY: Prentice-Hall

Baran, S. J., \& Davis, D. K. (2010). Mass communication theory-foundations, ferment \& future (3rd ed). USA: Thomson Wadsworth.

Baran, S. J., \& Davis, D. K. (2003). Mass communication theory-foundations, ferment \& future (3rd ed). USA: Thomson Wadsworth.

Cap (1983). The Power of Television: Cable Television and Women's Status In India. Unpublished Text.

Chinenye, N., Nnamdi, N., Okowa-Nwaebi, L. \& Ebeze, E. (2012). Satellite Television and Local Media Use Among Viewers in Satellite TELEVISION Households in the Southeast Geopolitical Zone of Nigeria. Higher Education of Social Science, 3 (3), 110.

Dominick, R. J. (2005). The dynamics of mass communication: media in the digital age (8th ed.). New York: McGraw Hill.

Domirani, T., Abbasali, G., Narges, H. \& Behnam, B. (2014). Investigation of the Cultural Impacts of Globalization on the National Media (Television). Current Research Journal of Social Sciences 6(2): 48-54.

Ekeh (1989). Communication and cultural domination New York: International Arts and Sciences Press.

Elaheh, G. Z. \& Afsaneh, M. (2014). The Impact of Satellite TELEVISION Channels on Lifestyle Changes for Women in Iran. International Journal of Business and Social Science . 5( 3):126-131.

Enna, E. (1994). The effects of violent television programmes on the attitudes of adolescents towards violence. Unpublished M.Ed Thesis, ABU Zaria.

Garba, V. (2015). Influence of Home Television Viewing on Academic Achievement of Children in Upper Basic Education in Kaduna State, Nigeria. Published Masters (M. Ed) Thesis submitted to the Department of Vocational Teacher Education (Home Economics Education), Faculty of Education, University of Nigeria, Nsukka.

Gerbner (1967). Cultural Imperialism: Essays on the Political Economy of Cultural Domination (Eds.).

Hofstede, G. (2001). Culture's Consequences: Comparing Values, Behaviors, Institutions and Organizations Across Nations.: Sage Publications, 2001. 
International Journal of Business and Management Review

Vol.8, No.2, pp.1-36, March 2020

Published by ECRTD-UK

Print ISSN: 2052-6393(Print), Online ISSN: 2052-6407(Online)

Inglehart, R. (1997). Modernization and postmodernization: Cultural, economic and political change in 43 societies. Princeton, NJ: Princeton University Press.

James, A. J., Daniel, C. A. \& Nnamdie, U. K. (2017). Influence of Foreign Television Programmes on the Westernization of Nigerian Youths. International Journal of International Relations, Media and Mass Communication Studies, 3(1):24-39.

Jaume G. \& Placido R. (2006), The Determinants of Television Audience for Spanish Football: A First Approach

Jenkayinfa (2002). Strategies for ensuring trustworthiness in qualitative research projects.

Jense. R. \& Oster. E. (2008). The Power of Television: Cable Television and Women's Status in India. Quarterly Journal of Economics.

Kanagy \& Kraybill. (1999). Globalization of Cultural Heritage: Issues, Impacts, and Inevitable Challenges for Nigeria. Library Philosophy and Practice.

Kanwal, G. \& Sukhmani (2011). A study of television viewership patterns among youngsters in Northern India. International Journal of Multidisciplinary Research, 1(5): I 141- 160

Kohn, M. L., \& Schooler, C. (1983). Work and personality. Norwood, NJ: Ablex.

Livingstone (2002). Fitting into their lives: A survey of Three Studies About Youth Media Usage. Newspaper Association of America Foundation.

Manit, S. \& Hitoshi, M. (2013). An Analysis of Factors Affecting the Adoption of Digital Terrestrial Television Services in Thailand. International Journal of Managing Public Sector Information and Communication Technologies, 4(2): 9-20.

McQuail, D. (2005). McQuail's Mass Communication Theory. Fifth E.d, Sage Publications

Merriam, S. (1998). Qualitative research and case study applications in education. San Francisco: Jossey-Bass Publishers.

Michael G. (2015). Determinants of Demand for Cable TV Services in the Era of Internet Communication Technologies. Honors College Theses. Paper 152.

Morse, J. M., Barrett, M., Mayan, M., Olson, K. \& Spiers, J. (2002). Verification Strategies for Establishing Reliability and Validity in Qualitative Research. International Journal of Qualitative Methods, 1(2): 1-5.

Nekmahmud M. D. \& Ferdush, R. (2016). Audience Attitude Towards Satellite TV Program and Advertising in Bangladesh. Global Media Journal, 14:27:1-11

Norsiah, A. H. (n.d.). (2003). The Internationalization of The Media: Does Local Values and Cultures Undermined? Unpublished Text

O’Donell, V. (2007). Television criticisms. Sage publications, Inc.

Obono, K., \& Madu, O. (2010). Programming Content of Nigerian Broadcast Media: Towards an Indigenizing Paradigm. EstudosemComunicação, 8.

Okonkwo (2008) The cultural Heritage. Asefeda Ventures. Lagos.

Oni, A. A. (2005). Globalization and its Implication on African Culture and Development: Challenges For Education. International Journal of African \& African American Studies, 4(2).

Onyiengo, S.I. (2014). Exposure to Sexual Content on Television and Youth Perceptions of Sexuality in Technical Training Institutions in Kenya.

Patricia, C. E. (2013). Television local contents: Conduit for cultural learning in Nigeria? Arabian Journal of Business and Management Review, 2(12):16-30.

Putnam, R. D. (1993). Making democracy work: Civic traditions in modern Italy. Princeton, NJ: Princeton University Press. 
International Journal of Business and Management Review

Vol.8, No.2, pp.1-36, March 2020

Published by ECRTD-UK

Print ISSN: 2052-6393(Print), Online ISSN: 2052-6407(Online)

Rideout, R. J. (2003). The dynamics of mass communication: media in the digital age (8th ed.). New York: Mc Graw Hill

Robaka, S. \& Mohammad, N. A. (2012). Effect of Satellite Television on the Culture of Bangladesh:The Viewers Perception. European Journal of Business and Management, 4(9):45-54.

Salman, A., Muhammad, S. J. \& Asghar, A. (2014). An analysis of Pakistan Television Corporation entertainment programs and its effects on youth. Asian Journal of Empirical Research, 4(5): 279-292.

Samovar, L. A., \& Porter, R. (2004). Communication between Cultures (5th ed.). USA: Thomson Wadsworth Learning Inc.

Samovar, L. A., Porter, R., \& McDaniel, E. F. (2010). Communication between cultures (7th ed.). USA: Thomson Wadsworth Learning Inc. overruled.

Schwartz, S. H. (1999). Cultural value differences: Some implications for work". Applied Psychology: An International Review, 48, 23-47.

Schwartz, S. H., Bardi, A., \& Bianchi, G. (2000). Value adaptation to the imposition and collapse of Communist regimes in Eastern Europe”. In S. A. Renshon and J. Duckitt (Eds.), Political Psychology: Cultural and Cross Cultural Perspectives (pp. 217-237). London: Macmillan.

Signorielli \& Micheal (2001). Television's world of work in the '90s. In T. Miller (Ed.), Critical concepts in media and cultural studies. London: Routledge.

Stanislaus I. (2014). Global Television and Cultural Promotion: Taming the Cultural Dilemma among Nigerian Youths. International Journal of Social Science and Humanity, 4(4):308-310

Van. (1990). Globalization of Media: Key Issues and Dimensions. European Journal of Scientific Research Toronto, Canada: Broadview Press Ltd.

Vivian, J. (2009). The media of mass communication (9th ed.). Boston, MA: Allyn and Bacon.

Weber, M. (1958). The Protestant ethic and the spirit of capitalism. New York: Scribners.

Williams, R. M., Jr. (1968). Values. In E. Sills (Ed.), International encyclopedia of the social sciences. New York: Macmillan.

Wilson, R., \& Wilson, R. (2001). Mass media, mass culture: an introduction (5th ed.). New York: McGraw Hill.

Yannis, M., Georgia, K., Katerina, K. \& Thodoris, L. (2009). Factors associated with television viewing time in toddlers and preschoolers in Greece: The Genesis Study. Oxford: Oxford University Press.

Yusuf, A. R. (2000). Impact of Globalization on Culture. Unpublished Text Education for Information, 22

Zixuan, Z. (2011). The Impact of American Television on Chinese College Students. M. Sc. Thesis, Wake Forest University Graduate School of Arts and Sciences,Winston-Salem, North Carolina. 